\title{
TRANSMISSION OF CARBONATED LIDOCAINE ACROSS THE PLACENTA DURING CAESAREAN SECTION*
}

\author{
Germain L. Houle, M.D., F.R.C.P.(c), Gordon S. Fox, M.D., F.R.C.P.(c) \\ and Michael G. ToRkington, M.B., Ch.B. $\dagger$
}

Several reports have been published from this department regarding the pharmacokinetics of carbonated lidocaine base during anaesthesia. ${ }^{1-3}$ In comparison with the hydrochloride salts, for epidural anaesthesia carbonated solutions of local anaesthetics have been shown to have a decreased latent period for onset of analgesia; a decreased latent period for complete spread of anaesthesia; a decreased requirement of mass of analgesic per spinal segment, and a greater spread of anaesthesia. Lidocaine $\mathrm{CO}_{2}$-base has been shown to be non-toxic to neural tissue. ${ }^{1}$

Carbonated solutions have been used for analgesia during caesarean section, ${ }^{2}$ but maternal and foetal concentrations of lidocaine base were not determined. This study was undertaken to investigate the vascular uptake of lidocaine $\mathrm{CO}_{2}$-base during epidural anaesthesia for caesarean section, and to determine whether resulting maternal and foetal lidocaine concentrations were within safe limits.

\section{METHOD}

Eighteen women who received epidural analgesia for elective caesarean section were studied. The indications for abdominal delivery were previous caesarean section and cephalopelvic disproportion. There were no other complicating features in this group of patients.

Premedication consisted of atropine sulphate $0.4 \mathrm{mg}$ intramuscularly one hour prior to surgery. The patient was placed in the sitting position, and a No. 16 Tuohy needle was inserted into the epidural space between the third and fourth lumbar vertebrae as previously described. ${ }^{4}$ Three millilitres of sterile saline were injected through the needle to open the epidural space and a polyvinyl catheter was inserted one needle-length cephalad. The patient was then placed in the supine position. Blood pressure was recorded using a sphygmomanometer cuff and auscultation. A No. 19-gauge "Butterfly"B needle was placed in the radial artery and a 5-ml sample of heparinized maternal arterial blood was obtained as a control for lidocaine determination. All patients received oxygen by face mask for at least ten minutes prior to delivery. ${ }^{5}$

Fresh epinephrine was added to the carbonated lidocaine to produce a 1:200,000 concentration of epinephrine in the local anaesthetic solution. Carbonated solutions contain the same concentration of anaesthetic base as stock 2 per cent hydrochloride salts. Epidural anaesthesia was initiated by injection of the local anaesthetic through the epidural catheter, when surgical preparation of the patient's

'Presented at the Annual Meeting, Canadian Anaesthestists' Society, 28 June 1971.

$\nmid$ Department of Anaesthesia, Royal Victoria Hospital, Montreal.

(1)Abbott Laboratories

Canad. Anaesth. Soc. J., vol. 18, no. 5, September 1971 
abdomen had begun. Maternal blood samples for lidocaine estimation were taken from the radial artery every three minutes after the injection of carbonated lidocaine and at the moment of delivery. Heparinized samples of umbilical venous and arterial blood were also obtained from a segment of doubly clamped umbilical cord obtained prior to placental separation. Lidocaine concentrations in all samples were determined by gas chromatography. ${ }^{6}$

Only one epidural injection of local anaesthetic was given prior to delivery of the baby. The elapsed time from induction of anaesthesia to delivery was recorded (T-D). The condition of the infant was recorded by allotting an Apgar score ${ }^{\tau}$ at one and five minutes after birth, and by noting the time to sustained respiration. ${ }^{8}$

Mean blood pressures were calculated using the formula (2Ps $+3 \mathrm{Pd}) / 5$ where Ps and Pd are sytolic and diastolic blood pressures respectively. The incidence of supine hypotension was noted and corrected by left uterine displacement and by the addition of methamphetamine $3 \mathrm{mg}$ to $6 \mathrm{mg}$ intravenously when required.

\section{RESULTS}

The mean maternal body weight, patient's height, total dose of lidocaine, and the dose in $\mathrm{mg} / \mathrm{kg}$ of body weight are shown in Table I. The mean total dose of $297 \mathrm{mg}$ and mean dose of $4.28 \mathrm{mg} / \mathrm{kg}$ are slightly less than the mean total dose of $316 \mathrm{mg}$ and $4.5 \mathrm{mg} / \mathrm{kg}$ previously used during caesarean section with lidocaine hydrochloride, ${ }^{4}$ but the differences are not statistically significant.

The rapid onset of epidural blockade allowed delivery of the infant in 19.2 (s.D. \pm 6.0 ) minutes from injection of the carbonated lidocaine (Table I). This is approximately ten minutes or thirty three per cent less than the time required when lidocaine hydrochloride is used. ${ }^{4}$

TABLE I

Maternal Body Weight and Height, Total Dose and Dose mg/KG; and the Elapsed Time From InJECTION OF Lidocaine $\mathrm{CO}_{2}$-Base to Delivery

\begin{tabular}{|l|c|c|c|c|c|}
\hline & & & \multicolumn{2}{|c|}{ LIDOCAINE-CO $_{2}$} & \\
\hline & WEIGHT (kg) & HEIGHT (cms) & TOTAL DOSE (mg) & ing/kg & M-D \\
\hline MEAN & 70.38 & 160.6 & 297.0 & 4.28 & 19.2 \\
\hline \pm S.D. & 11.84 & 11.8 & 31.0 & 0.68 & 6.0 \\
\hline
\end{tabular}

S.D. = Standard Deviation

$\mathrm{T}-\mathrm{D}=$ elapsed time to delivery

Apgar scores at one and five minutes, and the time to sustained rhythmic respirations (T.S.R.) are shown in Table II.

A fall in blood pressure occurred in twelve of eighteen patients, (66 per cent). This is a higher proportion than in our previously reported series ( 50 per cent).4,5 Table III shows the changes of mean blood pressure associated with epidural analgesia and delivery. As previously noted, ${ }^{4}$ hypotension is maximal at 4-6 minutes after injection of the local anaesthetic. Blood pressure was quickly restored to normal in all hypotensive patients; in ten cases by left uterine displacement only, and in two cases by left uterine displacement and a small intravenous dose of 
TABLE II

Apgar Scores and the Time to Sustained Rhythmic Respirations

\begin{tabular}{|c|c|c|c|}
\hline & 1 Minute & 5 Minutes & T. S.R. \\
\hline Mean & 7.5 & 8.8 & 21.2 \\
\hline \pm S .D. & 1.8 & 1.5 & 11.5 \\
\hline
\end{tabular}

T. S. R. - time to sustained rythmic respirations

TABLE III

Chancifs in Mean Blood Presscrt Assoctatro virth Epidural Anaesthesia and Delivery

\begin{tabular}{|c|c|c|c|c|}
\hline Time & Pre-operative & 3 mir. & 6 min. & Delivery \\
\hline Mean & 103.4 & 90.8 & 80.7 & 97.3 \\
\hline \pm .D. & 12.5 & 14.9 & 23.6 & 9.3 \\
\hline
\end{tabular}

S.D. = Standiud Deviation

methamphetamine (3-6 mg). None of the patients exhibited signs of central nervous system toxicity due to the local anaesthetic.

Mean maternal and foetal blood lidocaine concentrations calculated from the three minute samples are given in Table IV and the changes with time in mean maternal concentrations are plotted in Figure 1. Peak mean maternal concentrations $(1.81 \pm 0.50 \mu \mathrm{g} / \mathrm{ml}$ ) occurred fifteen minutes after epidural injections. However, the mean maternal lidocaine concentration at delivery of $1.93( \pm 0.54) \mu \mathrm{g} /$ $\mathrm{ml}$ was slightly higher, since this value was obtained from the samples taken precisely at delivery, a period ranging from 13 to 28 minutes after initiation of epidural blockade.

Mean lidocaine concentrations from foetal umbilical vein and artery were 0.91 $( \pm 0.66) \mu \mathrm{g} / \mathrm{ml}$ and $0.64( \pm 0.48) \mu \mathrm{g} / \mathrm{ml}$ respectively. The lidocaine concentration ratio between foetal umbilical vein and maternal artery was 0.47 and compares with a similar ratio of 0.6 found previously using the hydrochloride salt. ${ }^{4}$

Analgesia was judged satisfactory in all cases.

\section{Discussion}

Bromage $e^{1,2}$ has shown that less carbonated lidocaine is necessary for epidural analgesia than the orthodox hydrochloride salt. The amount of carbonated lidocaine used for this group of patients did not differ significantly from the amount of lidocaine hydrochloride used previously. ${ }^{4}$ No attempt was made to decrease the mass of lidocaine $\mathrm{CO}_{2}$-base to an absolute minimum, as this was felt to be an unwarranted gamble during caesarean section where an awake, comfortable patient 
TABLE IV

Maternal Artertal Lidocaine Concentrations at Three Minute Intervals after Epidural InJection of Lidocaine $\mathrm{CO}_{2}$-Base. Umbilical Cord Venous and Arterial Concentrations of Lidocaine at Delivery

LIDOCAINE CONCENTRATIONS $(\mu \mathrm{g})$

\begin{tabular}{|l|c|c|c|c|c|c|c|c|c|}
\hline & \multicolumn{7}{|c|}{ MATERNAL } \\
\hline Time* & 3 & 6 & 9 & 12 & 15 & 18 & 21 & 24 & Delivery \\
\hline Mean & 0.94 & 1.40 & 1.66 & 1.77 & 1.81 & 1.73 & 1.69 & 1.63 & 1.93 \\
\hline IS.D. & 0.48 & 0.50 & 0.53 & 0.67 & 0.50 & 0.55 & 0.55 & 0.72 & 0.54 \\
\hline N & 15 & 15 & 16 & 15 & 14 & 10 & 9 & 2 & 18 \\
\hline
\end{tabular}

\begin{tabular}{|l|c|c|}
\hline & UMBILICAL VEIN & UMBILICAL ARTERY \\
\hline Mean & 0.91 & 0.64 \\
\hline $\pm S . D$. & 0.66 & 0.48 \\
\hline$N$ & 18 & 16 \\
\hline
\end{tabular}

$$
\frac{C u v}{C m a}=0.47( \pm 0.36)
$$

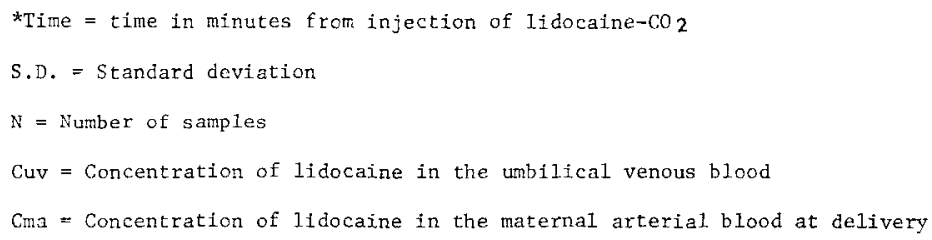

breathing 100 per cent oxygen from a face mask ${ }^{5}$ demands that an adequate level of anaesthesia be assured.

The 66 per cent incidence of hypotension encountered in this series compared to the 50 per cent with lidocaine hydrochloride could be secondary to a more extensive sympathetic blockade with carbonated lidocaine than with the hydrochloride solutions. If the effect of the local anaesthetic on the sympathetic nerves is enhanced by the $\mathrm{CO}_{2},{ }^{1}$ then the resulting blockade may add to the demands placed on the cardiovascular compensatory mechanism of patients in the supine position. Occasionally these demands could not be met by the circulation and the remaining sympathetic nerve supply, and consequently both left uterine displacement and intravenous methamphetamine were necessary in such cases.

The increased incidence of hypotension in this series may be part of the reason for the slight decrease in the one and five minute Apgar scores in comparison with previous work. We previously obtained mean Apgar scores of 8.1 and 9.6 at one minute and five minutes using lidocaine hydrochloride for epidural blockade, and 


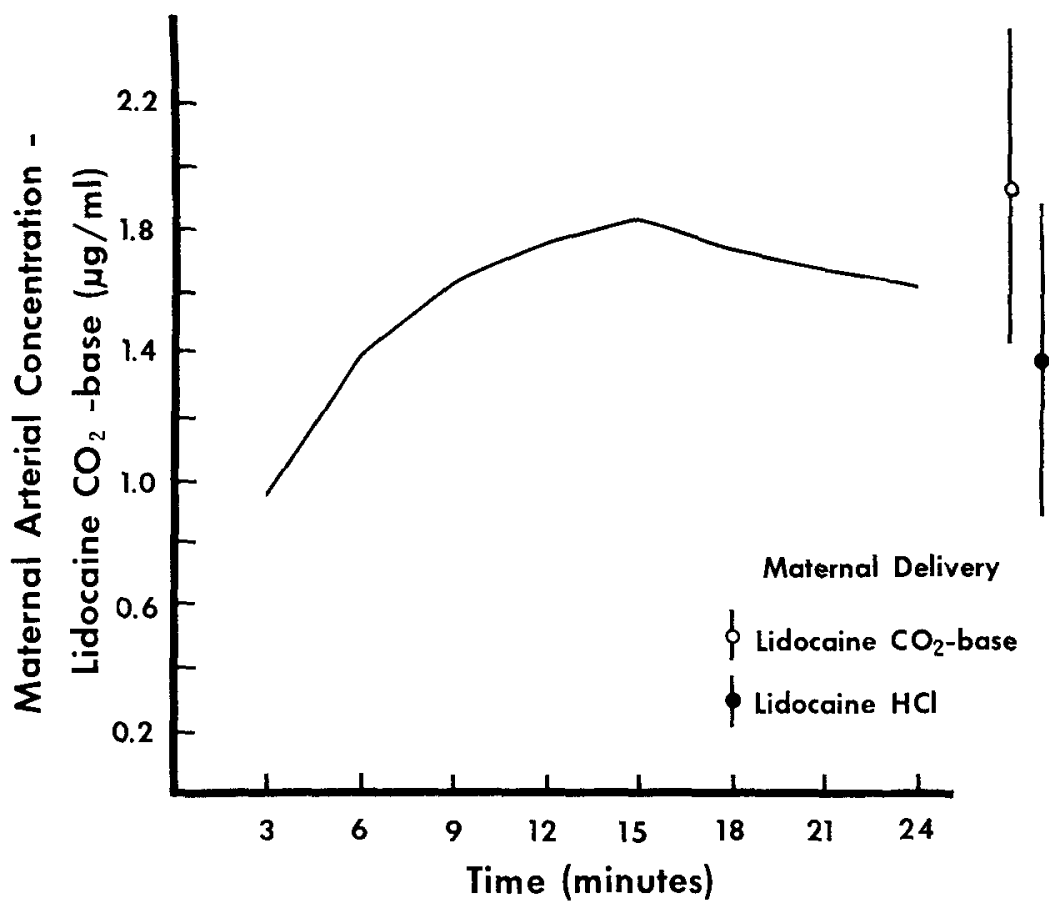

Ficure 1. Changes in maternal arterial concentration of lidocaine $\mathrm{CO}_{2}$-base after epidural block (Data in Table IV.). Maternal arterial lidocaine concentrations ( $\mu \mathrm{g} / \mathrm{ml} \pm$ S.D.) at delivery after epidural block with $2 \%$ lidocaine $\mathrm{CO}_{2}$-base and $2 \%$ lidocaine hydrochloride (Fox, G. S., and Houle, G. L., Canad. Anaesth. Soc. J., 16: 135-143, 1969.).

high inspired oxygen concentration to the mother. ${ }^{5}$ However, the time to sustained respirations in each series was practically identical ( 21.2 vs 22 seconds). All infants in the present series had one minute Apgar scores of 7 or better, with one exception, the scores in that particular case being 1 and 5 at one and five minutes post delivery. No reason for this could be found.

The elapsed time from injection of the local anaesthetic to delivery was shorter with the carbonated solution, but the period between delivery and peak maternal concentration ( 5 minutes) is similar to the intcrval between delivery and peak maternal concentration when the hydrochloride salt was used. ${ }^{4}$ Therefore in considering foetal lidocaine concentrations, which are dependent upon maternal concentrations, the earlier delivery achieved with lidocaine $\mathrm{CO}_{2}$-base offers no particular advantage. The shortened T-D is comparable to general anaesthetic techniques $^{5.9}$ and may be shorter than spinal anaesthesia. ${ }^{10}$

The mean maternal arterial blood concentration of $1.93( \pm 0.54) \mu \mathrm{g} / \mathrm{ml}$ is approximately 30 per cent higher than the concentration of $1.39( \pm 0.51) \mu \mathrm{g} / \mathrm{ml}$ found during caesarean section with stock 2 per cent lidocaine hydrochloride with 1:200,000 epinephrine. ${ }^{4}$ The lowest maternal concentration in this series was 1.0 $\mu \mathrm{g} / \mathrm{ml}$, while the highest was $2.6 \mu \mathrm{g} / \mathrm{ml}$. Regardless of the aetiology of the higher maternal concentrations, this blood level of local anaesthetic is well below the toxic threshold for lidocaine. ${ }^{11,12}$ 
Umbilical venous and arterial concentrations of $0.91( \pm 0.66) \mu \mathrm{g} / \mathrm{ml}$ and 0.64 $( \pm 0.48) \mu \mathrm{g} / \mathrm{ml}$ are higher than the $0.87( \pm 0.35) \mu \mathrm{g} / \mathrm{ml}$ and $0.51( \pm 0.25) \mu \mathrm{g} / \mathrm{ml}$ found with lidocaine hydrochloride. ${ }^{4}$ The higher foetal levels are directly related to the higher maternal levels. ${ }^{4}$ Foetal umbilical venous lidocaine concentration is approximately 50 per cent of the maternal arterial levels. This same value has been noted by others. ${ }^{13}$ The highest umbilical venous concentration found in this study was $2.0 \mu \mathrm{g} / \mathrm{ml}$. Foetal levels of less than $3.0 \mu \mathrm{g} / \mathrm{ml}$ have been associated with vigorous infants. ${ }^{13} \mathrm{It}$ appears certain that the foetal lidocaine concentrations found during this study are in the non-toxic range.

Finally, it should be noted that the practicing anaesthetist might consider it inconvenient to add fresh epinephrine to the carbonated lidocaine. However, should this local anaesthetic become commercially available, one will find the resultant speed and improved quality of anaesthesia well worth the additional time taken to introduce the epinephrine.

\section{Conclusions}

Carbonated lidocaine is a safe agent for producing maternal analgesia of rapid onset during epidural anaesthesia for elective caesarean section. Although maternal and foetal lidocaine concentrations are higher than those found with conventional lidocaine hydrochloride, these blood concentrations are below the toxic threshold in both instances.

\section{RÉSUMÉ}

La lidocaine carbonatée employée pour l’anesthésie péridurale pendant la césarienne élective est un agent qui est certain de produire une analgésie maternelle qui sera rapide. Même si les niveaux sanguins de la mère et du fetus sont un peu plus élevés qu’avec la lidocaine conventionelle, les concentrations sanguines sont encore beaucoup moins que la dose toxique chez la mère et le fetus.

\section{ACKNOWLEDGEMENTS}

We wish to thank Astra Chemicals Limited, Mississauga, Ontario, for support in carrying out this project and for supplying the lidocaine $\mathrm{CO}_{2}$-base solutions.

Appreciation is expressed to Mr. A. Edhorn, Chief Chemist, Astra Chemicals, for lidocaine concentration determinations.

\section{REFERENCES}

1. Bromage, P. R.; Burfoot, M. F.; Crowell, D. E.: \& Truant, A. P. Quality of Epidural Blockade III. Carbonated Local Anaesthetic Solutions. Brit. J. Anaesth., 39: 197 (1967).

2. Bromage, P. R. Improved Conduction Blockade in Surgery and Obstetrics: Carbonated Local Anesthetics. C.M.A.J., 97: 1377 (1967).

3. Bromage, P. R. A Comparison of the Hydrochloride and Carbon Dioxide Salts of Lidocaine and Prilocaine in Epidural Analgesia. Acta Anaesth. Scandinav, 55: Suplementum xvr (1965).

4. Fox, G. S. \& Houle, G. L. Transmission of Lidocaine Hydrochloride Across the Placenta During Caesarean Section. Canad. Anaesth. Soc. J., 16: 135 (1969). 
5. Fox, G. S. \& Houle, G. L. Acid-Base Studies in Elective Caesarean Section During Epidural Anaesthesia. Canad. Anaesth. Soc. J., 18: 60 (1971).

6. Edhorn, G. A. Determination of Lidocaine in Whole Blood By Gas Chromatography. Canad. Anaesth. Soc. J., 18: 189 (1971).

7. Apgar, V. A Proposal for a New Method of Evaluation of the Newborn Infant. Anesth. \& Analg., 32: 260 (1953).

8. Apgar, V.; Holaday, D. A.; Jones, L. S.; Weisbrot, I. M.; Prince, C. E.; \& Weiss, I. Comparison of Regional and General Anaesthesia in Obstetrics. J.A.M.A., 165: 2155 (1957).

9. Houle, G. L.; Fox, G. S.; \& Gertel, M. Methoxyflurane: Clinical and Laboratory Studies During Cesarean Section. Anesth. \& Analg., 48: 1011 (1970).

10. Marx, G. F.; Cosmi, E. V.; \& Wollman, S. B. Biochemical Status and Clinical Condition of Mother and Infant at Cesarean Section. Anesth. \& Analg., 48: 986 (1969).

11. Bromage, P. R. \& Robson, J. G. Concentration of Lignocaine in the Blood after Intravenous, Intramuscular, Epidural, and Endotracheal Administraton. Anaesthesia, 16: 461 (1961).

12. Foldes, F. F.; Malloy, R.; McNali, P. C.; \& Kaukal, L. R. Comparison of Toxicity of Intravenously Given Local Anaesthetic Agents in Man. J.A.M.A., 172: 1493 (1960).

13. Shnider, S. M. \& WAY, E. L. Plasma Levels of Lidocaine (Xylocaine ${ }^{\circledR}$ ) in Mother and Newborn Following Obstetrical Conduction Anesthesia: Clinical Applications. Anesthesiology, 29: 951 (1968). 